\title{
WET SNOW DEPTH FROM TANDEM-X SINGLE-PASS INSAR DEM DIFFERENCING
}

\author{
Silvan Leinss $^{(1)}$, Oleg Antropov ${ }^{(2)}$, Juho Vehviläinen $^{(3)}$,Juha Lemmetyinen $^{(3)}$, Irena Hajnsek $^{(1,4)}$, Jaan Praks $^{(2)}$ \\ (1) ETH Zurich, 8093 Zurich, Switzerland \\ (2) Department of Electronics and Nanoengineering, Aalto University, 00076 Aalto, Finland \\ (3) Finnish Meteorological Institute, 00101 Helsinki, Finland \\ (4) Microwave and Radar Institute, German Aerospace Center (DLR), 82234 Wessling, Germany
}

\begin{abstract}
Single pass radar interferometry (sp-InSAR) is a well established technique for generation of digital elevation models (DEM). Differencing two DEMs acquired at different times can reveal topographic changes. However snow depth estimation by DEM differencing is still an ongoing topic in radar research: in contrast to snow free surfaces, the snow surface elevation is difficult to detect either because of microwave penetration into dry snow or because of the weak backscatter return from wet snow which significantly decorrelates the interferometric signal. In this study we demonstrate first results of wet snow depth estimation by differencing sp-InSAR DEMs acquired by the TanDEM-X satellite mission. The results show, in contrast to dry snow, a clear sensitivity to wet snow. However, additionally to a high vertical sensitivity of a few ten centimeters a very low noise-equivalent-sigma-zero (NESZ) is crucial for successful snow depth estimation.
\end{abstract}

Index Terms - snow depth, wet snow, TanDEM-X, radar interferometry, DEM generation, DEM differencing.

\section{INTRODUCTION}

Snow provides a major source of freshwater for 1/6th of the Earth's population [1]. Consequently snow information such as snow depth (HS) or snow water equivalent (SWE) is required for needs of water resources management as well as flood predictions during the melt season. In situ snow depth can be measured relatively simply either by manual stick measurements or by automated ultrasonic stations. However, elevation, topography, vegetation and wind drift strongly affect the locally measured snow depth which is therefore not representative for larger regions. To determine snow depth over larger regions remote sensing methods come into play operating in the optical and microwave regime. Optical methods like Lidar [2] or photographic methods [3, 4] can provide $\mathrm{cm}$-scale snow depth maps but are limited to daylight, clear weather conditions and often to smaller areas. In contrast to passive microwave methods (e.g. [5, 6]), which are limited by the inherent coarse spatial resolution, active microwave methods based on single-pass interferometric synthetic aperture radar systems (sp-InSAR) can provide topographic information with a spatial resolution on the meter-scale and a vertical resolution on the sub-meter or even centimeter scale. Recently, retrieval of snow depth maps for wet snow cover has been demonstrated using the $35.7 \mathrm{GHz}$, airborne GLISTIN sp-InSAR system [7]. With the same system, compared to airborne LiDAR, a limited penetration of about 0.3 to $1 \mathrm{~m}$ in dry firn on the Greenland ice sheet was reported [8].

Due to the absence of a radar system in space with sufficiently high frequency to avoid penetration into dry snow, we focus in this study on data from the TanDEM-X satellite mission $[9,10]$ operating at $9.65 \mathrm{GHz}$. As the radar penetration into dry snow often exceeds the depth of a seasonal snowpack we do not expect any sensitivity to dry snow and focus therefore on snow depth determination during the snow melt season. Our method is based on differencing two digital elevation models (DEMs) where one was acquired during snow melt and one during snow free conditions. The method has already been demonstrated with TanDEM-X acquisitions over the Swiss Alps [11], but thus far lacks a comprehensive demonstration applying in situ data for validation. It is the purpose of this study to provide this demonstration.

\section{DATASET}

A dedicated experiment including a large set of ground measurements was designed for spring 2017 to demonstrate the potential of X-band sp-InSAR for depth determination of a melting snow pack. For the experiment, an area around the Kiilopää fell in the Urho Kekkonen national park in Saariselkä, Northern Finland, was chosen (E 27.53, $\left.\mathrm{N} 68.33^{\circ}\right)$. This site balances the following complementary requirements: 1) easy access for validation field campaigns, 2) remote enough to avoid conflicting acquisition interests and to allow for temporally dense coverage with TanDEM-X acquisitions of different modes, 3) sufficient topography and wind-induced snow drift to provide local-scale variability in snow depth, 4) gentle mountain slopes to avoid shadow, layover and phase-unwrapping problems, 5) low vegetation to avoid height bias and coherence loss due to vegetation. 
Table 1. Orbit parameters. $B_{\text {eff }}$ : effective baseline, HoA: height of ambiguity, NESZ: noise equivalent sigma zero; HS: high resolution spotlight; SM: stripmap; dual: HH,VV.

\begin{tabular}{l|cccc}
\hline rel. orbit, pol. & $B_{\text {eff }}(\mathrm{m})$ & HoA $(\mathrm{m})$ & $\theta_{\text {inc }}$ & NESZ \\
\hline $024(\mathrm{HS}, \mathrm{HH})$ & $109 \ldots 157$ & $67 \ldots 97$ & $54^{\circ}$ & $-20.8 \mathrm{~dB}$ \\
039 (SM,HH) & $117 \ldots 145$ & $53 \ldots .66$ & $44^{\circ}$ & $-25.2 \mathrm{~dB}$ \\
130 (SM,dual) & $110 \ldots 135$ & $46 . .56$ & $38^{\circ}$ & $-22.7 \mathrm{~dB}$ \\
\hline
\end{tabular}

Between July 2016 and June 2017 the test site was imaged from several TanDEM-X orbits with different modes (spotlight, stripmap, single-/dual-pol), incidence angles, and from ascending and descending orbits. Only ascending orbits were processed because descending orbits had a poor vertical sensitivity. The vertical sensitivity of ascending orbits were in the order of magnitude of the shallow tundra snow pack which rarely exceeded $1 \mathrm{~m}$. Table 1 shows the range of height of ambiguities (HoA) for the snow melt period between midMay and mid-June 2017. The snow free reference DEMs were acquired with a better vertical sensitivity corresponding to HoAs between 21 and $34 \mathrm{~m}$ (spotlight: $36 \ldots 47 \mathrm{~m}$ ).

Three validation campaigns supported the experiment. The campaigns consisted in manual snow bulk property measurements, snow depth and SWE, along several kilometer long transects (Figs. 1 and 2). Three pairs of radar reflectors were installed to verify the georeferencing of radar and ground data and for height calibration of the radar DEMs. Additionally, data from three weather stations were available (Fig. 2).

\section{METHOD}

For each orbit, the entire stack of single-look-complex data was co-registered to a common master scene. Interferograms were calculated for each acquisition date with the "flat"-earth phase (Earth ellipsoid) removed. A residual linear phase ramp caused by baseline-inaccuracies was subtracted. For the snow free reference acquisitions the remaining phase was converted to height and orthorectified using the ellipsoid to create a first guess of a raw DEM. The raw DEM and the geocoding table were iteratively updated to improve the simulated topographic phase. The DEM converged after 5-6 iterations such that the residual height difference (standard deviation between simulated and measured interferogram) of forest-free areas (coherence $>0.7)$ was below $0.7 \mathrm{~m}(1.0 \mathrm{~m}, 0.5 \mathrm{~m})$ for orbit 039 (orbit 024 , orbit 130). To further reduce the height noise of the final reference DEM, all snow free DEMs with baselines larger than $220 \mathrm{~m}$ were averaged. The final reference DEM was then used for topographic phase removal and geocoding of the entire stack, providing a DEM difference for each acquisition date. All stripmap radar data (DEM difference, backscatter signal $\sigma_{0}$, interferometric coherence) were converted to geographic coordinates with $5 \mathrm{~m}$ resolution (spotlight to $1 \mathrm{~m}$ resolution).
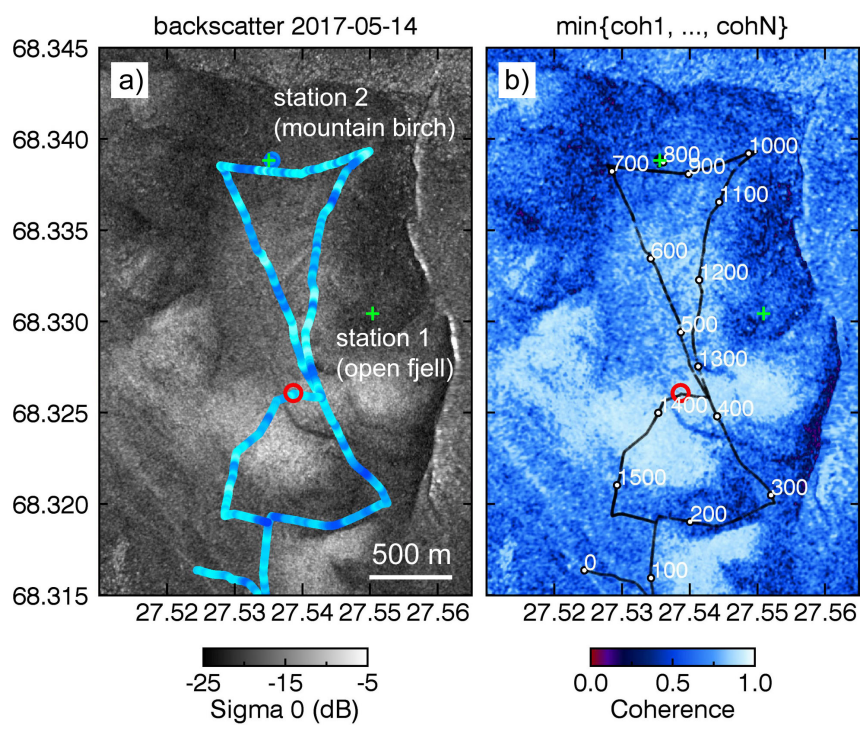

Fig. 1. (a) backscatter image (2017-05-14) with color coded snow depth transect from 2017-05-20 (blue). (b) minimum coherence of summer and winter interferograms. Numbers indicate field measurements along the transect. A radar reflector is located at the red circle; weather station 1 and 2 are at the green "+". Axis show latitude and longitude in degree.

Radar reflectors were well visible during dry snow conditions and were used to validate the geocoding. However, during snow melt some of the reflectors were no longer visible, likely due to wet snow cover. Therefore, they could not be used as a height reference. As a workaround a histogram of the height-differences was calculated and the height difference at the lowest 10\%-quantil was defined as zero height difference. For snow free acquisitions with a zero meandifference this caused a bias of about 1.3 standard deviations of the height difference. For wet snow covered scenes the bias is expected to be smaller.

To compare satellite with ground measurements a classification of wet snow cover was required. Wet snow was discriminated from dry snow by a backscatter threshold of 17.5 dB. Fig. 1(a,b) shows that valleys were covered by wet snow (low backscatter, low coherence) while hill tops were still covered by dry snow (bright backscatter, high coherence).

\section{RESULTS}

For successful DEM generation the backscatter signal must be significantly above the noise threshold (NESZ) to limit phase noise. The backscatter time series (Fig. 2: 3rd panel) show that during snow melt (gray shading) the backscatter signal falls frequently below the wet snow threshold of $-17.5 \mathrm{~dB}$ (blue solid line) which is close to the NESZ (dashed lines). As a result, snow depth can only be determined if a SARsystem provides a low enough NESZ which is well below the 


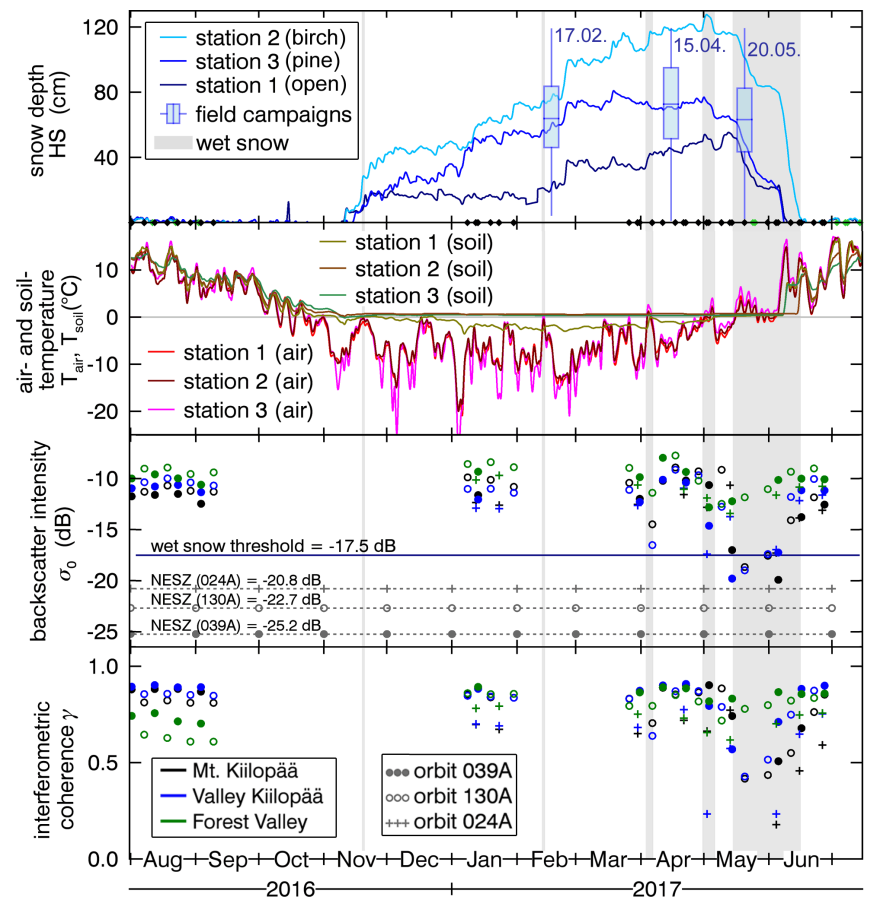

Fig. 2. 1st panel: snow depth from three weather stations on the test site (station 1:open fjell, 2: slope with mountain birch, 3: pine forest). Box plots summarize field campaigns (dates given) with median, upper and lower quartil, whiskers indicate min. / max. measured snow depth. Gray shadings show periods of snow melt $\left(T_{\text {air }}>0{ }^{\circ} \mathrm{C}\right)$. 2nd panel: air and soil temperature at $2 \mathrm{~m}$ and $-5 \mathrm{~cm}$. 3rd and 4th panel: backscatter intensity and coherence for three different orbits (indicated by symbols). Colors indicate three different locations (black $=$ hill top, blue $=$ valley, green $=$ forest $)$. dashed gray lines (3rd panel) show the NESZ for the three different orbits.

backscatter signal of wet snow. We found that only orbit 039 with an NESZ of -25.2 dB was suitable for snow depth estimation. For the spotlight acquisitions with an NESZ of -20.8 $\mathrm{dB}$ the coherence dropped below 0.3 during snow melt preventing any successful snow depth estimation. The scatterplot in Figure 3a shows how coherence decays for different land cover (color) and for different orbits (symbols) when the backscatter signal approaches the wet snow threshold.

The six rows in Fig. 4 show snow depth transects from spring 2017 (satellite data: red) together with the field measurements from 2017-05-20 (blue). A scatterplot (satellite over field data) for each date is shown on the right. Data points which are gray or transparent were classified as dry snow. Wet snow was only present for the the middle two acquisitions (2017-05-14 and 2017-06-05) where the backscatter signal (black line) falls below the threshold of -17.5 $\mathrm{dB}$ (dashed line). Considering the suboptimal vertical sensitivity on 2017-05-14 $(\mathrm{HoA}=53 \mathrm{~m})$ the satellite and ground transects show a reasonable agreement (Fig. 3b). Even two
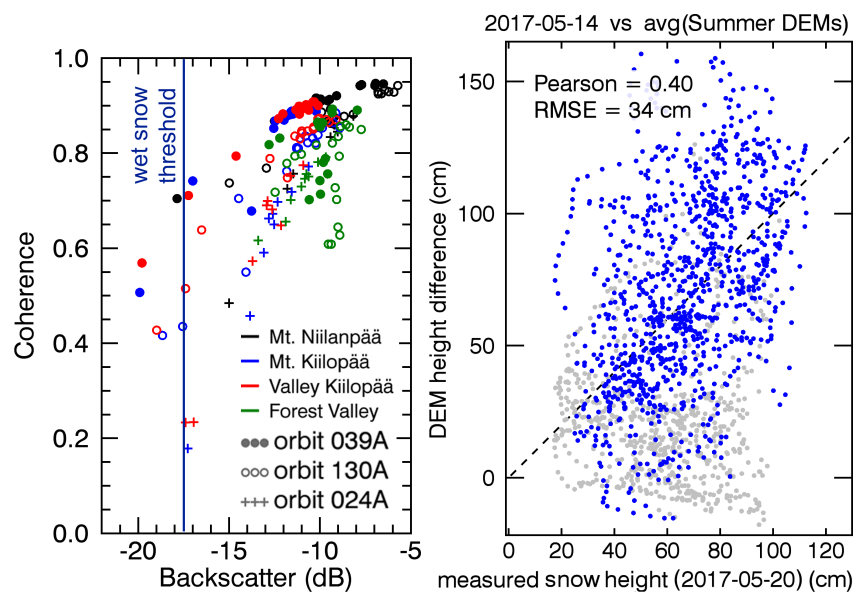

Fig. 3. (a) coherence over backscatter for different locations (color) and orbits (symbols). (b) scatterplot of snow depth from DEM differencing (2017-05-14 vs. summer) over field validation data from 2017-05-20. Blue dots are pixels covered by wet snow, gray pixels are pixels classified as dry snow.

weeks after the field measurements, on 2017-06-05, some weak correlation could still be found. During dry snow conditions (2017-04-22 and 2017-05-03) the radar snow depths are well below the field measurements and do not show any correlation with them. For future experiments in X-band we recommend NESZ below $-25 \mathrm{~dB}$ and HoA less than $30 \mathrm{~m}$.

\section{REFERENCES}

[1] T. P. Barnett, J. C. Adam, and D. P. Lettenmaier, "Potential impacts of a warming climate on water availability in snow-dominated regions," Nature, vol. 438, pp. 303309, 2005.

[2] J. S. Deems, T. H. Painter, and D. C. Finnegan, "Lidar measurement of snow depth: a review," Journal of Glaciology, vol. 59, no. 215, pp. 467-479, 2013.

[3] Y. Bühler, M. Marty, L. Egli, J. Veitinger, T. Jonas, P. Thee, and C. Ginzler, "Snow depth mapping in highalpine catchments using digital photogrammetry," The Cryosphere, vol. 9, no. 1, pp. 229-243, 2015.

[4] Y. Bühler, M. S. Adams, R. Bösch, and A. Stoffel, "Mapping snow depth in alpine terrain with unmanned aerial systems (uass): potential and limitations," The Cryosphere, vol. 10, no. 3, pp. 1075-1088, 2016.

[5] R. Kelly, "The amsr-e snow depth algorithm: Description and initial results," Journal of The Remote Sensing Society of Japan, vol. 29, no. 1, pp. 307-317, 2009.

[6] M. Takala, K. Luojus, J. Pulliainen, C. Derksen, J. Lemmetyinen, J.-P. Kärnä, J. Koskinen, and B. Bojkov, "Estimating northern hemisphere snow water equivalent for 


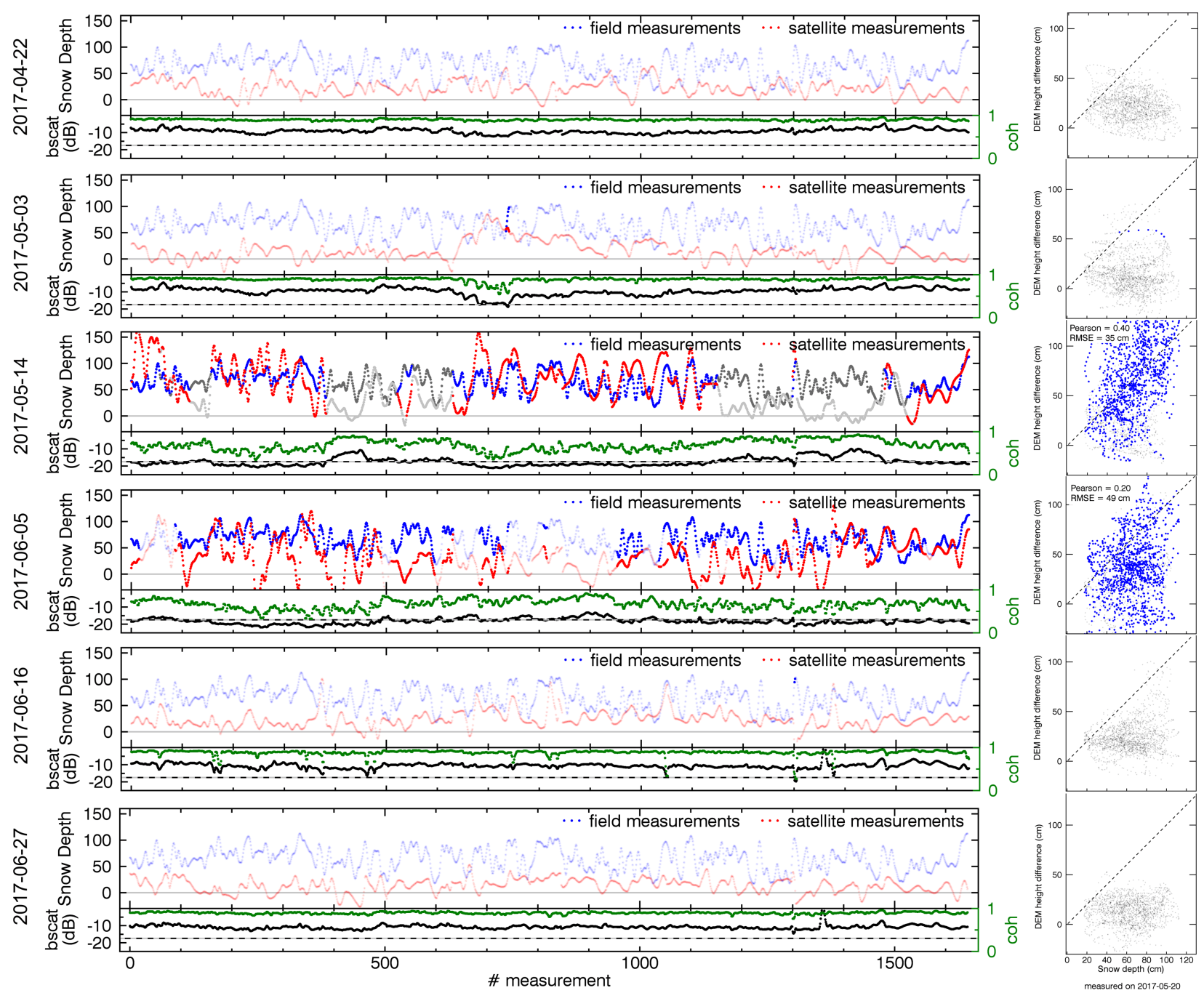

Fig. 4. Transects of TanDEM-X snow depth (red) for six different acquisitions from orbit 039A. Blue transects show field measurements from 2017-05-20. The black and green lines are backscatter $\left(\sigma_{0}\right)$ and the interferometric coherence along the transects. Wet snow was present only for the 3rd and 4th transect. A close-to-zero height difference was observed for the 5th and 6th transect (snow free conditions) and also for the 1st and 2nd transect which were acquired during dry snow conditions.

climate research through assimilation of space-borne radiometer data and ground-based measurements," $R e$ mote Sensing of Environment, vol. 115, no. 12, pp. 3517 $-3529,2011$.

[7] D. Moller, K. M. Andreadis, K. J. Bormann, S. Hensley, and T. H. Painter, "Mapping snow depth from ka-band interferometry: Proof of concept and comparison with scanning lidar retrievals," IEEE Geoscience and Remote Sensing Letters, vol. 14, no. 6, pp. 886-890, June 2017.

[8] S. Hensley, D. Moller, S. Oveisgharan, T. Michel, and $\mathrm{X}$. Wu, "Ka-band mapping and measurements of interferometric penetration of the greenland ice sheets by the glistin radar," Sel. Topics Appl. Earth Observations and Rem. Sens., vol. 9, no. 6, pp. 2436-2450, June 2016.
[9] G. Krieger, M. Zink, H. Fiedler, I. Hajnsek, M. Younis, S. Huber, M. Bachmann, J.H. Gonzalez, D. Schulze, J. Boer, M. Werner, and A. Moreira, "The TanDEMX Mission: Overview and status," in Radar Conference, 2009 IEEE, may 2009, pp. 1 -5.

[10] G. Krieger, M. Zink, M. Bachmann, et al., "TanDEM-X: A radar interferometer with two formation-flying satellites," Acta Astronautica, vol. 89, pp. 83 - 98, 2013.

[11] S. Leinss, "Depth, anisotropy, and water equivalent of snow estimated by radar interferometry and polarimetry, PhD thesis,” 2015, ETH Zürich. 